\title{
Mena and Vasodilator-Stimulated Phosphoprotein Are Required for Multiple Actin-Dependent Processes That Shape the Vertebrate Nervous System
}

\author{
A. Sheila Menzies, ${ }^{1}$ Attila Aszodi, ${ }^{2}$ Scott E. Williams, ${ }^{3}$ Alexander Pfeifer, ${ }^{4}$ Ann M. Wehman, ${ }^{1}$ Keow Lin Goh, ${ }^{1}$ \\ Carol A. Mason, ${ }^{3}$ Reinhard Fassler, ${ }^{2}$ and Frank B. Gertler ${ }^{1}$ \\ ${ }^{1}$ Department of Biology, Massachusetts Institute of Technology, Cambridge, Massachusetts 02139, ${ }^{2}$ Department for Molecular Medicine, Max Planck \\ Institute for Biochemistry, 82157 Martinsried, Germany, ${ }^{3}$ Departments of Pathology, Anatomy, and Cell Biology Center for Neurobiology and Behavior, \\ Columbia University College of Physicians and Surgeons, New York, New York 10032, and ${ }^{4}$ Department of Pharmacy, Ludwig-Maximilians University, \\ 81377 Munich, Germany
}

\begin{abstract}
Ena/vasodilator-stimulated phosphoprotein (VASP) proteins regulate the geometry of the actin cytoskeleton, thereby influencing cell morphology and motility. Analysis of invertebrate mutants implicates Ena/VASP function in several actin-dependent processes such as axon and dendritic guidance, cell migration, and dorsal closure. In vertebrates, genetic analysis of Ena/VASP function is hindered by the broad and overlapping expression of the three highly related family members Mena (Mammalian enabled), VASP, and EVL (Ena-VASP like). Mice deficient in either Mena or VASP exhibit subtle defects in forebrain commissure formation and platelet aggregation, respectively. In this study, we investigated the consequence of deleting both Mena and VASP. Mena ${ }^{-/-}$VASP ${ }^{-/-}$double mutants die perinatally and display defects in neurulation, craniofacial structures, and the formation of several fiber tracts in the CNS and peripheral nervous system.
\end{abstract}

Key words: Mena; vasodilator-stimulated phosphoprotein; VASP; Ena/VASP; actin; cytoskeleton; axon guidance; neurulation; commissure

\section{Introduction}

Regulation of cell morphology and motility is fundamental to nervous system development. During early embryogenesis, transformation of the neuroepithelium from a relatively flat layer into a tube-like structure involves the concerted regulation of cell motility within the neuroepithelium, cell shape changes at future hinge points, and elevation and fusion of neural folds. As development proceeds, neuroepithelial cells proliferate, ultimately giving rise to differentiated neurons. Migration of neurons to their appropriate location in the developing nervous system and proper extension and pathfinding of axons and dendrites ensures the formation of appropriate synaptic connections. All of these morphogenetic processes require actin-driven changes in cell shape, such that perturbation of actin dynamics either by treatment with actin depolymerizing drugs (Morriss-Kay and Tuckett, 1985; Bentley and Toroian-Raymond, 1986; Davidson and

Received March 22, 2004; revised July 28, 2004; accepted July 28, 2004.

This work was supported by National Eye Institute Training Grant T32 EY 13933 (S.E.W.) and National Institutes of Health Grants EY012736 (C.A.M.) and GM58801 (F.B.G.). A.S.M. was supported by a David Koch Graduate Fellowship. We thank R. Bronson for helpful discussions and expert assistance in histological examination. We also thank A. Caron for help in histology; C. Candida, K. O'Brien, and A. Dousis for mouse maintenance and genotyping; M. Barzik for providing GST-VASP protein; T. Jessell for the gift of islet- $1 / 2$ antibodies; and members of the Gertler laboratory for critical reading of this manuscript.

Correspondence should be addressed to Dr. Frank B. Gertler, Massachusetts Institute of Technology, Department of Biology, 68-270, 77 Massachusetts Avenue, Cambridge, MA 02139-4307. E-mail: fgertler@mit.edu.

D0I:10.1523/JNEUROSCI.1057-04.2004

Copyright $\odot 2004$ Society for Neuroscience $\quad$ 0270-6474/04/248029-10\$15.00/0
Keller, 1999) or genetic deletion of actin-regulatory genes (Juriloff and Harris, 2000; Meyer and Feldman, 2002) results in neurulation, cell migration, and axon guidance defects.

The Ena/Vasodilator-stimulated phosphoprotein (VASP) family of actin-regulatory proteins functions in a variety of cell types to regulate cell morphology and motility (Krause et al., 2003). Drosophila Ena was originally identified as a genetic suppressor of $a b l$-dependent phenotypes (Gertler et al., 1990). The three vertebrate orthologs are Mena (Mammalian enabled), VASP, and EVL (Ena-VASP like). Ena/VASP proteins localize to focal adhesions and areas requiring dynamic remodeling of the actin cytoskeleton, including lamellipodial protrusions and filopodial tips. The ability of Ena/VASP proteins to bind F-actin and protect growing filaments from being capped regulates the geometry of the actin network. Ena/VASP activity promotes the formation of long unbranched actin filaments (Bear et al., 2002). The resulting filaments are arranged into different structures depending on the cell type. In Dictyostelium and neurons, Ena/ VASP promotes the formation of filopodial structures composed of bundled F-actin (Han et al., 2002; Lebrand et al., 2004).

Genetic analysis in Drosophila and Caenorhabditis elegans demonstrates that Ena/VASP proteins are required for the guidance of cell bodies, axons, and dendrites. Ena/VASP functions downstream of $\mathrm{Abl}$ and the axon guidance receptors Robo (Bashaw et al., 2000), Dlar (Wills et al., 1999), Deleted in colorectal cancer (DCC) (Gitai et al., 2003), and Unc-5 (Colavita and 
Culotti, 1998). Furthermore, these genetic interactions are supported by biochemical interactions between Ena/VASP and Abl (Gertler et al., 1996; Howe et al., 2002), Dlar (Wills et al., 1999), and Robo (Bashaw et al., 2000). Additionally, Ena functions with Abl during dorsal closure of the Drosophila embryo, a process dependent on convergent extension of epithelial cells at the dorsal midline (Grevengoed et al., 2001) and analogous to neurulation in vertebrates. Analysis of $\mathrm{Mena}^{-/-}$mice reveals defective formation of the corpus callosum (CC), dorsal hippocampal commisure (DHC), and ventral hippocampal commissure (VHC) in 50\% of mutants (Lanier et al., 1999). Mena function in neurulation is revealed through genetic interaction with the actin monomer binding protein Profilin I, in which half of $\mathrm{Mena}^{->}$ $-\mathrm{ProI}^{+/-}$mice do not close their cephalic neural tube (Lanier et al., 1999). VASP $P^{-/-}$mice do not exhibit nervous system defects, but VASP-deficient platelets have an increased aggregation response to known stimulants and partial resistance to cAMP and cGMP effects (Aszodi et al., 1999; Hauser et al., 1999).

Mena and VASP function interchangeably in fibroblast motility assays (Loureiro et al., 2002) and are expressed in a broad and overlapping expression pattern during development and adulthood (Aszodi et al., 1999; Lanier et al., 1999; Gambaryan et al., 2001). Given the limited and partially penetrant phenotypes of $\mathrm{Mena}^{-/-}$and $\mathrm{VASP}^{-/-}$mice, we hypothesized that mice lacking both Mena and VASP would exhibit more severe defects than single-mutant animals. In the present study, we report that Mena $^{-/-} V^{-1 S P^{-/-}}\left(M^{-/-} V^{-/-}\right)$mice die perinatally and display defects in neurulation, craniofacial structures, and several axonal pathways in the CNS and peripheral nervous system.

\section{Materials and Methods}

Animals and histology. Mena (Lanier et al., 1999) and VASP (Aszodi et al., 1999) mutant mice were previously generated. The MenaVASP (MV) line was initiated by crossing Mena mutants maintained on either a $129 \mathrm{sv}$ $\left(M^{129}\right)$ or c57BL6 $\left(M^{c 57}\right)$ background to VASP mutants maintained on a mixed background. The resulting $M V$ mice were intercrossed for several generations, and the progenies were analyzed at various stages of development. Although no $M V$ backcrossed lines were analyzed, littermate controls $\left(M^{+/-} V^{+/-}, M^{+/-} V^{+/+}\right.$, and $\left.M^{+/+} V^{+/-}\right)$did not exhibit phenotypes displayed by mutants. Furthermore, the callosal defects in $M^{-/-} V^{+/-}$mice are identical to those previously reported for $M^{-/-}$mice, which were the F1 hybrid progeny of mating between $M^{129}$ and $M^{\text {c57 }}$ mice $\left(M^{129 / \mathrm{c} 57 \mathrm{Fl-l-}}\right)$. In the present study, callosal development was analyzed in mutant $M^{-/-} V^{+/-}$and $M^{129 / \mathrm{c} 57 \mathrm{Fl}-/-}$ mice and compared with control $M^{+/-} V^{+/-}$and $M^{129 / c 57} \mathrm{Fl+l-}$ littermates, respectively. Mice heterozygous for Mena and VASP were intercrossed to generate double null progeny at an expected frequency of 1 of 16 . To increase the fraction of double null progeny, $M^{+/-} V^{-1-}$ intercrosses and $M^{+/-} V^{+/-}$ $\times M^{+/-} V^{-/-}$mating were also performed. For timed-pregnant mating, embryonic day 0 (E0) was considered the morning the vaginal plug was detected. Silver staining of adult brain sections and SEM of E9.5 embryos was performed as described previously (Lanier et al., 1999). Hematoxylin and eosin (H/E) staining was performed on $5 \mu \mathrm{m}$ paraffin sections using a standard technique.

Immunohistochemistry. Mena (2197) and VASP (2010) polyclonal antibodies were purified using N-terminal Mena and glutathione $S$-transferase (GST)-VASP protein affinity columns, respectively. Immunolabeling with Mena antibodies (2197, affinity purified 2197, and monoclonal H8C2G5) and VASP affinity purified 2010 antibodies was performed on $10 \mu \mathrm{m}$ frozen sections of $4 \%$ paraformaldehyde (PFA) fixed E10.5 embryos and E17 heads. Sections were blocked with $10 \%$ serum $/ 10 \%$ BSA in PBST (PBS plus $0.05 \%$ Tween 20 ) and incubated with primary and secondary antibodies diluted in $1 \%$ serum/1\%BSA/PBS at $4^{\circ} \mathrm{C}$ overnight, followed by several washes with PBST. Sections were counterstained with 4',6'-diamidino-2-phenylindole (DAPI). Phalloidin-Alexa 594 (Molecular Probes, Eugene, OR) was used at 1:300 to label F-actin in E10.5 frozen sections. Double and triple labeling of Mena and VASP with neurofilament 2H3 (1:4; Developmental Studies Hybridoma Bank, University of Iowa, Iowa City, IA), islet 1/2 (1:10000; gift from T. Jessell, Columbia University, New York, NY), and/or glutamate transporter (GLAST) (1:2000; Chemicon, Temecula, CA) in E14.5 heads was performed with minor modifications. Frozen sections $(20 \mu \mathrm{m})$ were blocked for 60 min with $10 \%$ normal goat serum in PBS plus $0.2 \%$ Triton $\mathrm{X}-100$ and then incubated with primary antibodies diluted in block overnight at $4^{\circ} \mathrm{C}$. Primary antibodies were detected with cyanine 3 (Cy3)conjugated, Cy5-conjugated (Jackson ImmunoResearch, West Grove, PA), or AlexaFluor 488- and Alexa 568-conjugated (Molecular Probes) secondary antibodies or goat anti-rabbit biotin (Vector Laboratories, Burlingame, CA) followed by streptavidin-FITC (PharMingen, San Diego, CA).

Immunolabeling with anti-GFAP antibodies (DAKO, Carpinteria, CA) was performed on $50 \mu \mathrm{m}$ vibratome sections of heads stored in $4 \%$ PFA as described previously (Shu and Richards, 2001) with minor modifications. Briefly, sections were treated with $1 \% \mathrm{NaB}$ and washed with PBS. Overnight incubation with anti-cow GFAP antibody (1:1000 in 2\% goat serum $/ 0.2 \%$ Triton X-100/PBS) and $2 \mathrm{hr}$ incubation with goat antirabbit biotin (1:600 in 0.2\% Triton X-100/PBS) and streptavidin-FITC were performed at room temperature and followed by PBS washes. Sections were counterstained with DAPI, mounted onto slides, and imaged with an epifluorescent microscope.

Anti-neurofilament labeling of E10.5 whole-mount embryos was performed as described previously (Hogan, 1994). Briefly, embryos were fixed in $\mathrm{MeOH}$ :DMSO $(4: 1)$ overnight at $4^{\circ} \mathrm{C}$, washed with $\mathrm{MeOH}$ : DMSO: $\mathrm{H}_{2} \mathrm{O}_{2}$ (4:1:1) at room temperature to block endogenous peroxidase activity, and then stored in $100 \% \mathrm{MeOH}$ at $-20^{\circ} \mathrm{C}$. For staining, embryos were rehydrated in successive washes of $50 \% \mathrm{MeOH}, \mathrm{PBS}$, and PBSMT (PBS; $2 \%$ nonfat dry milk; 0.5\% Triton X-100). Embryos were incubated with primary neurofilament $2 \mathrm{H} 3$ and secondary donkey antimouse HRP antibodies at 1:500 in PBSMT/10\% donkey serum overnight at $4^{\circ} \mathrm{C}$, followed by several washes with PBSMT. HRP activity was detected with $\mathrm{DAB} / \mathrm{NiCl}$ solution (Vector Laboratories). Embryos were washed with PBT (PBS/0.2\% BSA/0.5\% Triton X-100), postfixed with $4 \%$ PFA, and cleared with methyl salicylate before imaging with a CCD camera attached to a dissecting microscope.

Carbocyanine dye labeling. Embryonic brains were fixed with $4 \%$ paraformaldehyde. 1,1' -Dioctadecyl 3,3,3',3' -tetramethylindocarbocyanine perchlorate (DiI) crystals were injected laterally along the midline to label callosal fibers. For double-labeling experiments, brains were cut to expose the fimbria where 4-(4-dihexadecylaminostyryl)- $N$-methylpyridinium iodide (DiA) crystals were placed as described previously (Livy and Wahlsten, 1997). Brains were placed in 4\% PFA for 4-8 weeks to allow diffusion of lipophilic dyes along axons. Subsequently, brains were sucrose infiltrated and vibratome sectioned coronally or horizontally. Sections were counterstained with DAPI, mounted onto slides, and imaged with an epifluorescent microscope.

To label retinal ganglion cell (RGC) projections, small crystals of DiI were applied to the optic nerve head of one retina to completely label all axons exiting the eye. Labeled samples were incubated for $4-7 \mathrm{~d}$ at $37^{\circ} \mathrm{C}$ in PBS plus $0.02 \% \mathrm{NaN}_{3}$ (Sigma, St. Louis, MO). After labeling, both optic nerves were severed, and the intact forebrain containing the optic nerves, optic chiasm, and optic tract was dissected from the skull. Brains were imaged as whole-mounts, with the chiasm on the ventral surface, using an epifluorescent dissecting stereomicroscope. Guidance errors were judged blind to genotype.

\section{Results}

\section{Mena and VASP proteins are broadly expressed} during development

Ena/VASP proteins are broadly expressed, and two or more family members have been detected in all tissue lysates examined by Western blot analysis (Lanier et al., 1999). Within the nervous system, Mena and VASP expression was detectable early in development and persisted throughout embryogenesis and into adulthood. In the E10.5 embryo, Mena and VASP were highly ex- 

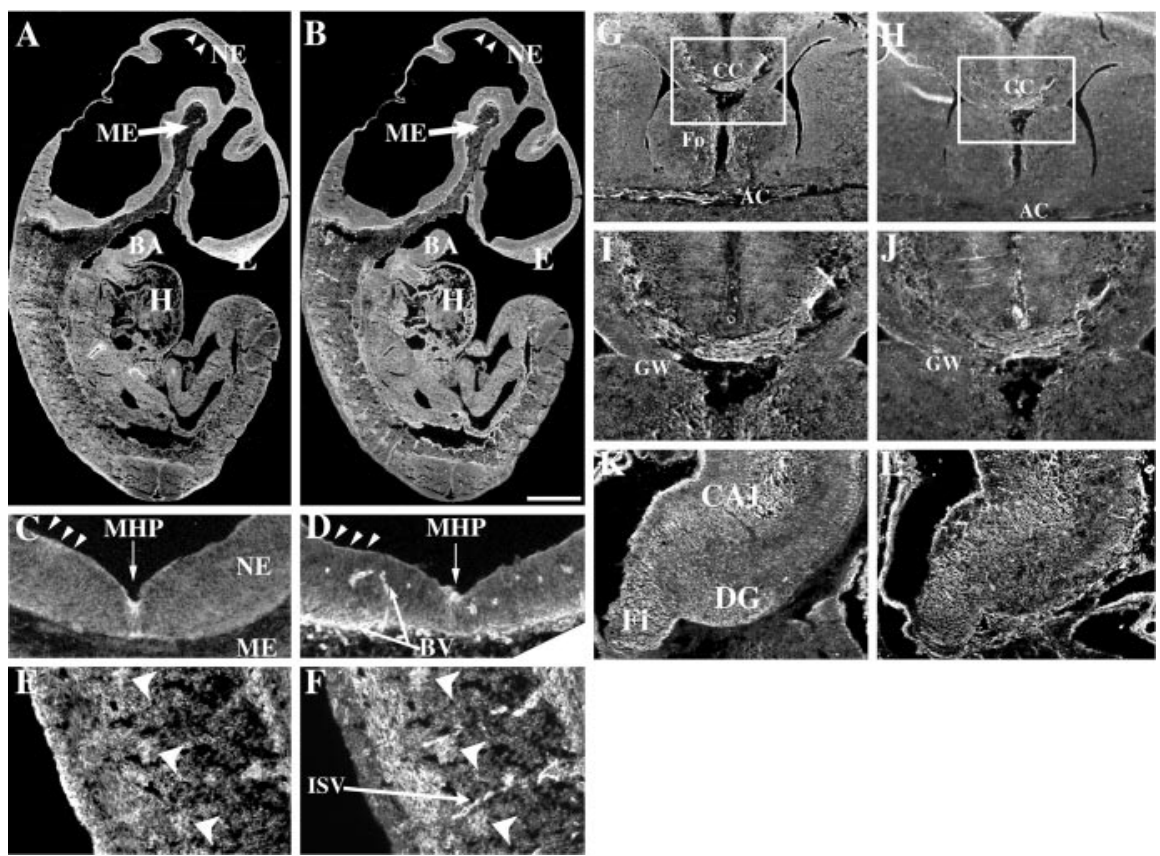

Figure 1. Developmental expression of Mena and VASP protein. $A-F$, At E10.5, Mena $(A, C, E)$ and VASP $(B, D, F)$ proteins are broadly distributed. In sagittal embryo sections, Mena $(A)$ and VASP $(B)$ are detected in several structures, including the neuroepithelium (NE), underlying mesoderm (ME), overlying ectoderm (E), branchial arch (BA), and heart $(\mathrm{H})$. Frontal sections through the cephalic neural tube show that Mena ( $C$ and VASP $(D)$ are expressed throughout the neuroepithelium but concentrated at the apical surface ( $A-D$, arrowheads) and cells in the MHP. VASP is also detected in blood vessels (BV) within and surrounding the neural tube. VASP $(F)$ is also highly expressed in the intersomitic vessels (ISV) running between the dorsal root ganglia, which also express VASP ( $F$, arrowheads) and Mena ( $E$, arrowheads). In the E17 brain, Mena $(G, I, K)$ and VASP $(H, J, L)$ are label axons traveling in the $C($, fornix ( $(\mathrm{Fo})$, and AC. Mena and VASP expression in the midline region (magnification of boxed areas in $G$ and $H$ ) are shown in / and J, respectively. Mena and VASP label the corpus callosum as well as the GW. Within the hippocampus, Mena ( $K$ ) and VASP $(L)$ are enriched in the $C A 1$ region and fimbria (Fi), whereas Mena but not VASP is enriched in the dentate gyrus (DG). Scale bar: (in B) $A, B, 500 \mu \mathrm{m} ; C, D, I-L, 120 \mu \mathrm{m} ; E, F, 100 \mu \mathrm{m} ; G, H, 300 \mu \mathrm{m}$.

pressed in the neuroepithelium, which gives rise to the future brain and spinal cord (Fig. $1 A-D$ ). Mena and VASP proteins were distributed throughout the stratified neuroepithelium but concentrated along the apical surface facing the lumen of the neural tube and in neuroepithelial cells residing in the medial hinge point (MHP) of the cephalic neural tube (Fig. 1C,D). Apical constriction of these hinge point cells allows bending of the neural tube, one of the early events in neural tube closure. Mena and VASP were also highly expressed by dorsal root ganglia (DRG) and motor neurons within the spinal cord (Fig. 1E,F) (data not shown). Expression was not restricted to the nervous system, because both Mena and VASP were abundant in the ectoderm overlying the neuroepithelium, branchial arch, and heart, whereas lower levels were detected in the mesoderm underlying the neuroepithelium (Fig. $1 A, B)$. Unlike Mena, VASP was highly expressed in the vasculature system and labeled vessels within the neural tube, vessels lining the neural tube (Fig. 1D), and vessels of the intersomitic artery where Mena expression was minimal (Fig. $1 F$ ).

In the developing brain, Mena and VASP proteins were expressed in all regions and labeled several major commissural fiber tracts (Fig. 1G-J) (Lanier et al., 1999). Mena and VASP were expressed by projection neurons within the cortex and were seen along their axons traveling within the corpus callosum. The optic chiasm, hippocampal commissure, and anterior commissure (AC) were also strongly labeled with Mena and to a lesser extent VASP (Fig. $1 G, H$ ) (data not shown). Mena and VASP were also detected near the lateral ventricles in the glial wedge (GW), a structure important for the formation of the corpus callosum
(Fig. 1I,J). Within the hippocampus, Mena was detected in the fimbria, CA1, and dentate gyrus regions, whereas VASP was expressed in the fimbria and CA1 region but not in the dentate gyrus (Fig. $1 K, L)$. To ensure the specificity of the Mena and VASP signal, $M^{-/-}$and $V^{-1}$ sections and no primary antibody controls were used (data not shown).

\section{Mena and VASP-deficient mice die perinatally and display severe neural tube defects and facial malformations} Mena and VASP double heterozygotes were intercrossed to generate mice deficient in both Mena and VASP. Recovery of $M^{-1-} V^{-1-}$ adults was extremely rare (supplemental material, available at www. jneurosci.org). To increase the frequency of $M^{-/-} V^{-/-}$progeny, $M^{+/-} V^{-1-}$ mice were also used for mating. From over 200 litters, only three $M^{-1-} V^{-1-}$ adults were recovered. Mating with male $M^{-/-} V^{-1-}$ mice revealed that these mutants were fertile. From the $M^{+/-} V^{+/-}$intercross, $\sim 40 \%$ fewer $M^{-/-} V^{+/-}$progeny were recovered than expected. To determine whether $M^{-1-} V^{-1-}$ and $M^{-/-} V^{+/-}$animals died in utero, litters were harvested at middle (E10.5) and late (E18.5) stages of embryogenesis. $M^{-1-} V^{\prime-}$ and $M^{-/-} V^{+/-}$ embryos were recovered at nearly the expected Mendelian frequencies at both embryonic stages (supplemental material, available at www.jneurosci.org), indicating that these animals died perinatally.

External examination of embryos harvested at E10.5-E18.5 revealed that $64 \%$ of $M^{-1-} V^{-1-}$ embryos $(n=164)$ displayed defective closure of their cephalic neural tube (Fig. 2A). Neural tube defects were not observed in any control $M^{+/-} V^{+/-}$littermates $(n=105)$. Failure of anterior neural tube closure disrupted normal brain development and resulted in exencephaly (Fig. 2B). Exencephalic $M^{-1-} V^{-1-}$ mutants exhibited severe disruption of regionalization and lamination of brain structures (data not shown). $M^{-/-} V^{-/-}$embryos also displayed malformations in neural crest cell-derived facial structures that ranged from moderate deformities of the nose and mouth to severe facial clefts (Fig. 2B). Similar neural tube defects were seen in $18 \%$ of $M^{+/-} V^{-1-}$ embryos $(n=313)$. Only four $M^{-1-} V^{+/-}$embryos $(n=56)$ displayed neurulation defects. The frequency of exencephaly did not completely account for the reduced viability of $M^{-/-} V^{-/-}$and $M^{-\prime-} V^{+/-}$animals. Further analysis of these mutants revealed additional defects in nervous system development.

Defective cephalic neural tube closure was observed as early as E9.5, a stage when control littermates had closed neural tubes (Fig. 2A). Histological examination showed significant differences in neural tube defects between individual animals. In many $M^{-1-} V^{-1-}$ mutants, the neural folds were completely splayed apart (Fig. 2D). In other less severe mutants, the neuroepithelial folds bent medially but exhibited defects at the dorsal midline such as failure of neural fold fusion (Fig. $2 F$ ). Invaginations of the neuroep- 
ithelial folds were frequently seen in the ventral and dorsal neural tube. Phalloidinstained sections of exencephalic mutants revealed an accumulation of filamentous actin at the base of the cephalic neural folds at E10.5 (Fig. 2D). No actin accumulation was observed in control animals (Fig. 2C,E) or in nonexencephalic mutants (Fig. $2 F$ ).

\section{Sensory and motor branches of spinal nerves exhibit defects in axon projections}

Neurons with cell bodies that reside in the DRG and motor column of the spinal cord extend axons that comprise the sensory and motor branches of spinal nerves, respectively. At the forelimb level, cervical 4-8 and thoracic 1 spinal nerves converge to form the branchial plexus at the base of the forelimb bud. Spinal nerve development was analyzed by anti-neurofilament whole-mount staining of E10.5 embryos. Although the DRG and motor column appeared normal, spinal nerve development was perturbed in $25 \%$ of $M^{-/-} V^{-1-}$ mutants $(n=16)$ (Fig. 3). Spinal nerve defects were not observed in littermates containing at least one wild-type allele of Mena or VASP. Defects included failed extension, presence of misrouted fibers, and reduced converge of spinal nerves forming the branchial plexus. These results indicate that Mena and VASP function are required at various steps of spinal nerve development.

Despite the neurulation defects, development of nearby cranial ganglia and cranial nerves appeared undisturbed in exencephalic $M^{-/-} V^{-1-}$ mice (Fig. 3). Histological analysis of embryonic spinal cords did not reveal defects in spinal commissure formation, indicating that deletion of Mena and VASP affected select populations of neurons in the spinal cord and neighboring dorsal root ganglia.

\section{Formation of several forebrain commissures is dependent on Mena and VASP}

Commissures are composed of axons that cross the midline and form connections in the contralateral side of the body. There are four major forebrain commissures connecting the two brain hemispheres: the CC, DHC, VHC, and AC (Fig. 4A). Analysis of brains of nonexencephalic $M^{-/-} V^{-/-}$mutants revealed the complete absence of these four major forebrain commissures (Fig. $4 C$ ). Axons of the CC, DHC, and VHC arrived at the midline but appeared bundled and did not cross, whereas AC axons did not arrive at the midline and therefore did not cross. These defects were completely penetrant in the five $M^{-/-} V^{--}$mutants examined [two adult and three late stage embryo (E18.5, E17.5) brains] (Table 1). Cortical lamination appeared similar in control and mutant brains (data not shown).

Analysis of mutants with varying numbers of Mena and VASP alleles confirmed a dose-sensitive effect of these genes on forebrain commissure formation. Approximately $80 \%$ of $\mathrm{M}^{-/-} V^{+/-}$ mice exhibited CC, DHC, and VHC defects, whereas a subset of these mutants exhibited AC defects (Table 1). The CC and DHC were completely absent in $M^{-/-} V^{+/-}$brains, whereas the VHC $\mu \mathrm{m}$; insets, $100 \mu \mathrm{m}$.
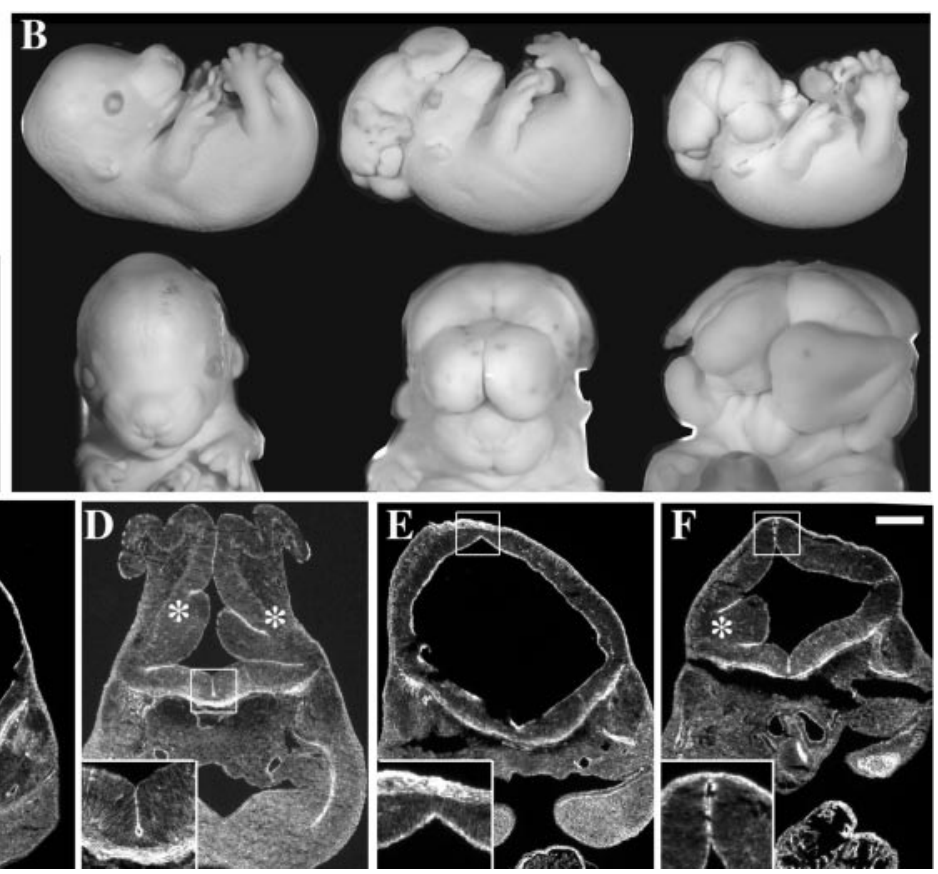

re 2. Neurulation and craniofacial defects. $A$, SEM of E9.5 cephalic neural tubes of control (top) and $M^{-/-} V^{-/-}$(bottom) 作 mutant neuroepithelia contain several invaginations (asterisks) that are not observed in controls $(C, E)$. Scale bar: (in $F)(-F, 250$

was reduced, forming caudally but not rostrally (Fig. $4 B$ ). Only a few $\mathrm{AC}$ axons reached the midplane and crossed. Identical CC, DHC, and VHC defects occurred in $50 \%$ of $M^{-1-}$ brains; however, the AC did form in $M^{-/-}$mutants (Lanier et al., 1999). Alternatively, although VASP-deficient mutants did not exhibit commissure defects, $\sim 30 \%$ of $M^{+/-} V^{-/-}$mutants exhibited identical CC, DHC, and VHC defects as $M^{-/-}$and $M^{-/-} V^{+/-}$ mice (Table 1). Defects in the four major forebrain commissures were most severe and completely penetrant in mutants lacking all wild-type Mena and VASP alleles. Therefore, forebrain commissure formation requires both Mena and VASP function but is more sensitive to deletion of Mena.

Mena and VASP function in corpus callosum development was studied in more detail. Embryonic brains of control and mutant littermates were examined at stages when callosal axons normally arrive and cross the midline. Callosal fibers were labeled with DiI to determine when and where the pathfinding defects occurred. In coronal sections of E16.5 control brains, callosal fibers arrived at the midline region but had not yet crossed (Fig. $5 A$ ). At this stage, mutant fibers arrived at a similar position near the midline with no indication of pathfinding problems. One day later at E17.5, many control callosal fibers crossed the midline at a level dorsal to the GW (Fig. 5B); however, in mutant brains, callosal fibers had not crossed. Rather, mutant callosal fibers traveled further ventrally and formed a bundle of misrouted fibers called a Probst bundle (Probst, 1901), positioned below the GW. Normally, the CC and VHC appeared as two distinct structures along the entire rostrocaudal axis. In caudal sections of mutant brains, however, labeled callosal fibers contacted the VHC ectopically. This was more obvious in horizontal sections of E17.5 


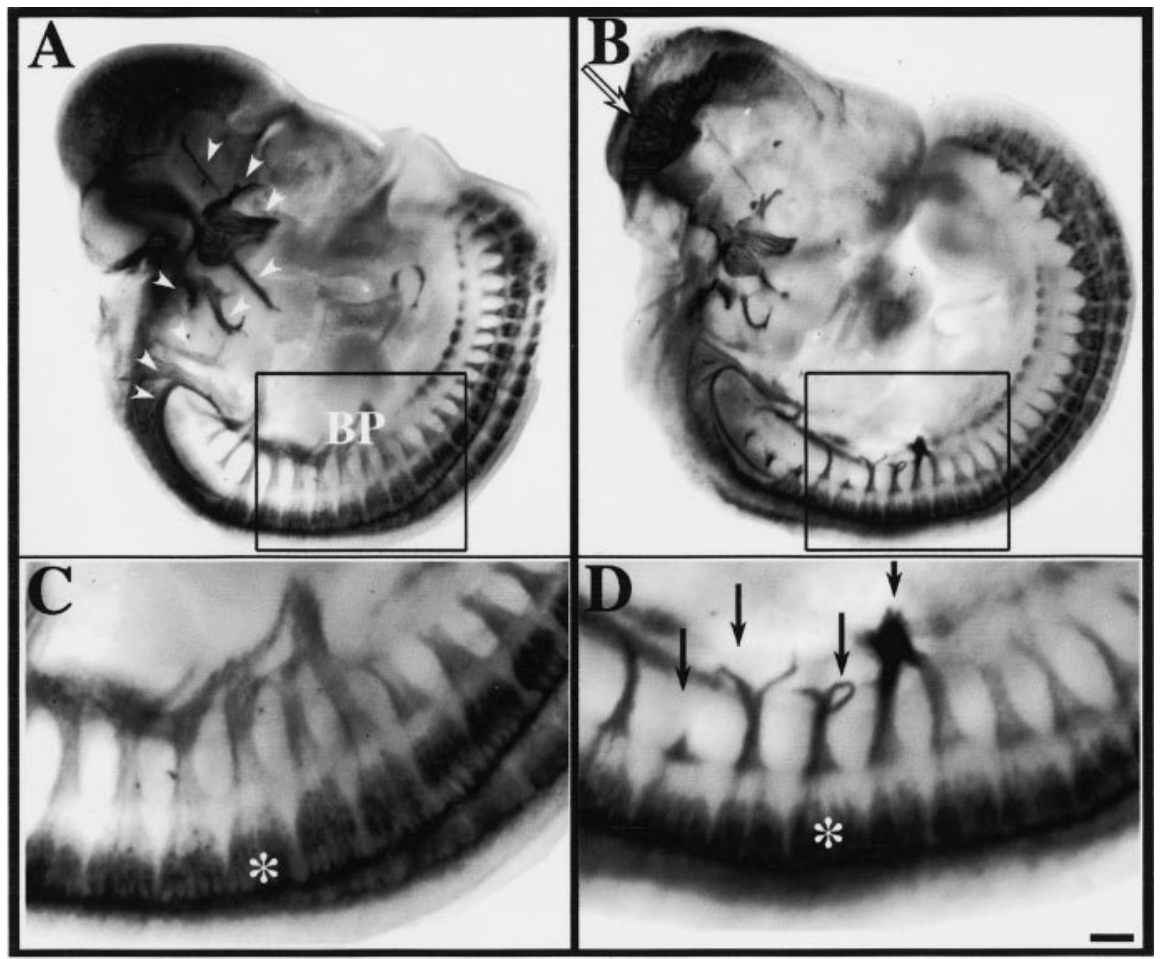

Figure 3. Spinal nerve defects. $A-D$, Whole-mount anti-neurofilament immunohistochemistry of $E 10.5$ control $(A, C)$ and $M^{-/-} V^{-1-}(B, D)$ littermates. Boxed areas in $A$ and $B$ are enlarged in $C$ and $D$, respectively. Spinal nerves extend and converge to form the branchial plexus (BP) in control animals $(A, C) \cdot \ln M^{-/-} V^{-/-}$mutants, spinal nerves are misrouted and/or have failed to extend ( $D$, arrows). Cranial ganglia, cranial nerves (arrowheads), and dorsal root ganglia (asterisks indicate corresponding DRGs) appear to develop normally in both control $(A)$ and mutant $(B)$ embryos. Note the open neural tube in the mutant $(B$, open arrows). Scale bar: (in D) $A, B, 250 \mu \mathrm{m} ; C, D, 100 \mu \mathrm{m}$.

brains where fibers of the CC and VHC were labeled with DiI and DiA, respectively (Fig. 5C). Unlike controls, mutant callosal fibers traveled in a caudoventral direction to contact the VHC.

Because misrouting of callosal fibers occurred near the midline, mutant brains were examined for development of midline structures. Fusion of the cerebral hemispheres and guidance signals from the GW and indusium griseum (IG) has been shown to influence callosal guidance at the midline (Ozaki and Wahlsten, 1993; Shu and Richards, 2001). Hemisphere fusion occurs when the walls of the sulcus medianus telencephali medii (SMTM) bend medially and fuse with the pial membrane (Wahlsten, 1981) (Fig. 6A). Callosal fibers travel underneath the fusion point to arrive in the contralateral hemisphere. Examination of embryonic brains revealed that hemisphere fusion is perturbed in mutant brains (Fig. 6B). The walls of the SMTM appeared to bend toward and touch the pia as seen in brains of control littermates; however, in mutants, the pial membrane extended further ventrally. Hemisphere fusion also appeared perturbed in the mutant diencephalon. In mutant brains, a gap existed where normally the walls of the thalamus meet forming the interthalamic adhesion (Fig. $6 B$, inset). Anterior commissure fibers cross ventral to this fusion point.

Glia of the GW and IG both express the repulsive guidance factor, Slit, and are thought to guide callosal fibers across the midline via a surround repulsion mechanism (Shu and Richards, 2001). The GW is composed of glia with cell bodies that reside in the lateral ventricles and processes that extend toward the midline. IG glia are positioned at the dorsal midline where the hemispheres fuse. GFAP staining revealed that at E16.5, a stage when callosal axons arrive in the midline region, GW development was similar in mutant and littermate controls (Fig. 6C,D). In contrast, at E17.5 mutant callosal fibers were bundled into Probst bundles and the GW appeared distorted (Fig. 6E,F). Furthermore, GFAP-positive fibers were found within the Probst bundle. These fibers are likely glial extension of IG glia that were mispositioned, resulting from improper hemisphere fusion.

\section{Optic chiasm formation in Mena mutants is perturbed}

The optic chiasm is an X-shaped midline structure comprised of the axons of RGCs, which are the sole projection neurons from the eye. Unlike many other commissures in the brain, the optic chiasm is a partial decussation. Most retinal axons cross the midline and project into the contralateral optic tract. However, a minority of retinal fibers, originating primarily from ventrotemporal retina, do not cross and instead join the optic tract on the ipsilateral side of the brain (Fig. $7 D-F$, arrow). Retinal axons reach the chiasm midline beginning at $\sim \mathrm{E} 12.5$, but the first ipsilaterally projecting axons do not appear until $\sim$ E14 (Colello and Guillery, 1990; Godement et al., 1990; Sretavan, 1990). Mena protein was enriched throughout the RGC layer in E14.5 retina (Fig. 7A) and was expressed on retinal axons throughout their trajectory (Fig. 7A$C$ ). Mena is also found throughout the ventral diencephalon (Fig. 7C). Mena mRNA expression by in situ hybridization yielded consistent results (data not shown). VASP protein appears to be minimally expressed in RGCs and the ventral diencephalon (data not shown).

To determine whether Ena/VASP proteins are required for proper formation of the optic chiasm, we examined the retinal projections in Mena and VASP mutant embryos by unilateral anterograde labeling with DiI (Fig. 7D-I) (data not shown). In control animals (Fig. $7 D, F, H$ ), most crossed and uncrossed RGC fibers remained tightly bundled within the optic nerves and optic tracts, although a few axons strayed caudally from the midline. However, in $M^{-/-}$mutants at E13.5-E14.5, many axons became defasciculated around the midline and strayed into inappropriate regions posterior to the chiasm, ipsilateral and contralateral to the labeled optic nerve (Fig. $7 E, G$, arrowheads). By E16.5, these guidance errors appeared to be largely corrected in the mutants (Fig. 7I) $(n=6)$. Errors were made by both ipsilaterally and contralaterally projecting axons and were observed in $100 \%$ of $M^{-1-}$ and $M^{-/-} V^{+/-}$embryos at younger ages $(n=12)$. In contrast, such errors were never observed in control animals $\left(M^{+/-}\right.$or $\left.M^{+/+} ; n=12\right)$. Furthermore, this phenotype did not seem to depend on VASP function, because $M^{+/-} V^{\prime-}(n=4)$ and $M^{+/-} V^{+/-}$animals $(n=8)$ are indistinguishable from controls (data not shown). This is consistent with our observation that VASP is expressed at very low levels in the retina and chiasm region.

Because the corpus callosum defects observed in $M^{-/-} V^{-/-}$ mutants can be attributed to, at least in part, a failure of the cerebral hemisphere fusion, we investigated whether midline 
structures of the ventral diencephalon on which the chiasm forms appear normal in $M^{-/-}$embryos. Two groups of midline cells are implicated in RGC axon guidance at the midline, the midline glial palisade expressing the radial glial antigens RC2 and GLAST, and the early born chiasm neurons that express stage-specific embryonic antigen 1 . Both midline populations appeared normal in $M^{-/-}$embryos compared with controls (data not shown).

\section{Discussion}

Ena/VASP function is critical for several actin-dependent morphogenic processes. Mena and VASP are required for viability and the formation of several neuralderived structures. Neural tube, craniofacial, spinal nerve, and anterior commissure defects are exhibited in $M^{-1-} V^{-1-}$ mice but not single $M^{-/-}$and $V^{-/}$mutants, indicating the required function of both genes for development of these structures. Although deletion of VASP enhances many Mena-dependent axon guidance phenotypes in the forebrain, the optic chiasm phenotype reveals a third category of defects, which is dependent on Mena but not VASP. The variable penetrance of defects in the single-mutant animals may reflect the relative abundance of Mena and VASP proteins in the affected cell types.

\section{Ena/VASP function in neurulation}

Neurulation is a major morphogenetic event requiring the cooperative efforts of intrinsic forces within the neuroepithelium and extrinsic forces in the surrounding tissue (Smith and Schoenwolf, 1997). Neuroepithelial cells in future hinge point regions serve as attachment sites to the underlying tissue and become wedge-shaped by constriction of actin filaments in the apical neuroepithelium and basal expansion by interkinetic nuclear migration. Bending of the neural plate at the MHP and dorsolateral hinge points (DLHPs) and elevation of the neural folds transforms the cephalic neural tube into a diamond-shaped structure. Cell rearrangement within the dorsal neural tube appears to promote the apposition of neural folds (Davidson et al., 1999), which fuse subsequently at the dorsal surface.

Neurulation defects are observed in several gene-targeted mutants of actin regulatory proteins, many of which directly bind actin filaments, including the nonreceptor tyrosine kinases Arg and $\mathrm{Abl}$, the protein kinase $\mathrm{C}$ substrates MARCKS (myristoylated alanine-rich $C$ kinase substrate) and MacMARCKS (MARCKSrelated protein), p190RhoGAP, Vinculin, and Shroom (Juriloff and Harris, 2000) as well as proteins involved in cell adhesion such as N-cadherin (Radice et al., 1997), neural cell adhesion molecule (Cremer et al., 1994), integrins (De Arcangelis et al., 1999), and the bidirectional signaling molecule ephrin-5A (Holmberg et al., 2000).

Requirement for Profilin I, an actin monomer binding protein, in neurulation is observed when Profilin I mutations are introduced into the Mena mutant background. Approximately $50 \%$ of $M^{-/-} P^{+/-}$mutants are exencephalic (Lanier et al., 1999). Interestingly, $V^{-1-} P^{+/-}$mice are recovered at nearly the Mendelian frequency and are viable and fertile (A. Wehman and F. Gertler, unpublished observations). Mena-Profilin interaction may facilitate actin monomer incorporation into growing filaments and promote filament elongation, which produces the cell shape changes necessary for neurulation.

Cephalic neurulation is highly sensitive to perturbation of actin dynamics, whereas spinal neurulation is relatively insensitive (Ybot-Gonzalez and Copp, 1999). Neurulation defects in $M^{-/-} V^{-/-}$mice are restricted to the cephalic neural tube, resulting in exencephaly but not spina bifida. Examination of E10.5 $M^{-/-} V^{-/-}$neural tubes reveals disorganized and invaginated neuroepithelia. In most mutants, neural folds are completely splayed apart and do not meet at the midline, whereas in other mutants, neural folds bend inward but do not fuse. Mena and VASP are expressed in both the neuroepithelium and surrounding cephalic mesenchyme and epidermis. Within the neuroepi- 

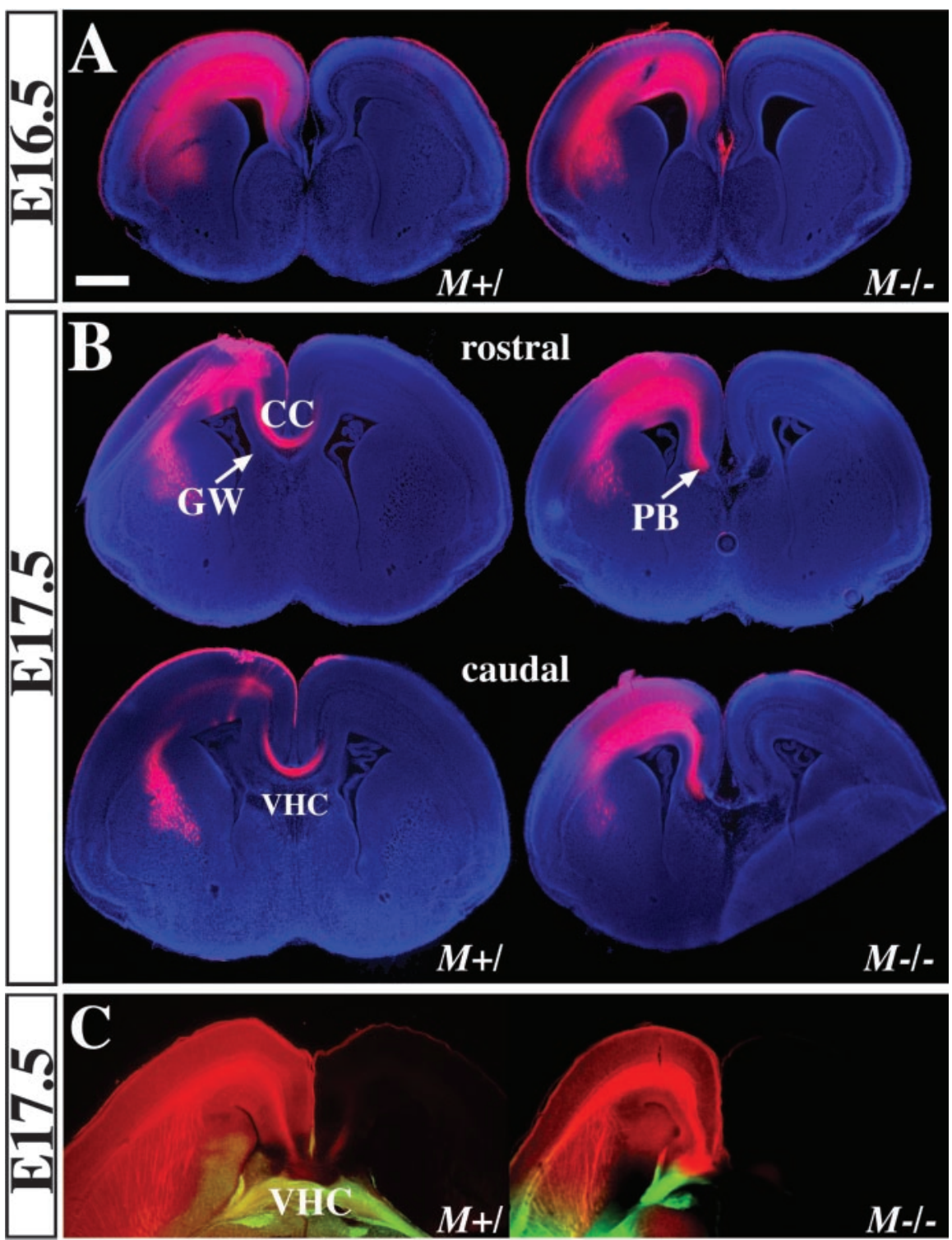

Figure 5. Corpus callosum development. $A, B$, Dil-labeled callosal fibers (red) in coronal sections counterstained with DAP (blue). $A$, At E16.5, callosal fibers in control and $M^{-/-}$brains have arrived at similar positions near the midline region but have not yet crossed. $B$, At E17.5, callosal fibers in control brains (left panel) have crossed the midline and project into the contralateral cortex. Callosal fibers (CC) cross at a level dorsal to the GW, shown in rostral (top panel) and caudal (bottom panel) sections of the same brain. However, in $\mathrm{M}^{-/-}$brains (right panel), callosal fibers travel further ventrally, do not cross the midline, and form Probst bundles (PB) adjacent to the midline. In caudal sections of the same brain, mutant callosal fibers contact the VHC. $C$, Dil-labeled callosal fibers (red) and DiA-labeled hippocampal commissure fibers (green) in horizontal sections of E17.5 brains. In control brains, the callosal and hippocampal commissure fibers appear as distinct tracts. In mutant brains, the callosal fibers (red) travel in a greater caudoventral direction to reach the VHC (green). Scale bar (in A), $400 \mu \mathrm{m}$.

thelium, Mena and VASP are enriched at the apical surface where $\mathrm{F}$-actin, catenins, cadherins, and $\mathrm{Abl} / \mathrm{Arg}$ are also concentrated. Mena and VASP are particularly enriched at the MHP and may be required within the neuroepithelium, principally for apical constriction of cells at future hinge points to bend the neural plate and/or ensure attachment to the underlying tissue. Failure at DLHPs could result in the severe phenotype in which the neural folds are splayed apart. The milder neurulation defects (invaginated neuroepithelium and defective fusion of dorsal neural folds) exhibited by $M^{-/-} V^{-1-}$ mutants may result from other cellular functions such as adhesion of neural folds and rearrangement of cells within the neuroepithelium. Additionally, Mena and VASP may function in the underlying mesoderm and surface ectoderm to provide the protrusive force necessary to elevate the folds and facilitate fusion at the dorsal midline.

Genetic studies show that Drosophila Ena and Abl genetically interact in dorsal closure, a process analogous to vertebrate neurulation (Grevengoed et al., 2001). Mice deficient in the vertebrate Abl orthologs, Arg and Abl, exhibit similar cephalic neurulation defects as $M^{-/-} V^{-/-}$ mutants (Koleske et al., 1998). Ena/VASP proteins bind Abl (Gertler et al., 1996; Howe et al., 2002) and may function with Abl family members in neurulation. In $a b l$ mutant flies, Ena is mislocalized, suggesting that $\mathrm{Abl}$ regulates Ena localization (Grevengoed et al., 2001). Moreover, in $a b l$ mutants, ectopic actin accumulations in apical microvilli are observed in areas of mislocalized Ena. Reduction in Ena levels suppresses this phenotype, suggesting that Ena promotes the formation of these actin-rich structures (Grevengoed et al., 2003). Alternatively, Abl may regulate Ena/VASP function by direct phosphorylation. Although the combined overexpression of Abl, Mena and the Abi 1 adaptor protein results in phosphorylation of Mena at Y296 (Tani et al., 2003), this site is not conserved in the other family members. Whether endogenous Mena and VASP are physiological Abl substrates remains to be determined.

\section{Ena/VASP function in axon guidance}

Many of the axonal defects seen in $M^{-/-} V^{-/-}$mice involve midline guidance decisions, a major choice point in the developing nervous system, where axons must choose to cross to the contralateral side or remain ipsilateral. After encountering the midline, growth cones assume complex morphologies displaying numerous filopodia (Godement et al., 1994). Growth cone filopodia serve important exploratory roles and integrate diverse guidance signals into an overall directional response (Dickson, 2002). Ena/VASP proteins localize to filopodial tips and have been shown to regulate filopodial formation. Therefore, the critical requirement for dynamic reorganization of the actin cytoskeleton at the midline and other choice points may be compromised in Ena/ VASP-deficient axons and result in the observed pathfinding defects. Recently, it has been shown that inhibiting the function of all Ena/ VASP proteins in cultured hippocampal neurons blocks the filopodial response to netrin-1, supporting a cell-autonomous function of Ena/VASP proteins in axon guidance (Lebrand et al., 2004). Furthermore, Ena/VASP proteins are phosphorylated at a conserved protein kinase A (PKA) site after netrin stimulation. Attractive or repulsive responses to guidance cues, such as netrin and slit, can be reversed by changes in the intracellular concentrations of cyclic nucleotides (cAMP and cGMP) (Song and Poo, 1999). PKA/PKG-dependent phosphoregulation of Ena/VASP proteins, which is crucial for Ena/ 
VASP function in fibroblast random motility and in platelets, may be one mechanism to modulate growth cone response to given guidance factors.

Callosal defects observed in $\mathrm{M}^{-/-}$and $M^{-/-} V^{+/-}$mutants are similar to phenotypes of mice deficient in netrin-1 (Serafini et al., 1996), DCC (Fazeli et al., 1997), and Slit2 (Bagri et al., 2002). Slitmediated repulsion and netrin-mediated attraction are thought to guide callosal axons toward and across the midline. Callosal fibers pass through a region flanked by Slit expressing GW and IG glia (Shu and Richards, 2001) to arrive at the midline where netrin is expressed. When Slit2 expression is perturbed in the GW, callosal axons travel ventrally into the septum (Shu et al., 2003). The fact that Mena mutant axons travel more ventrally before bundling may indicate a defect in their response to Slit-mediated repulsion.

The presence of hemisphere fusion defects in mutants exhibiting forebrain commissure defects raises the possibility that axonal pathway defects may be a consequence of the altered terrain. Interestingly, terminal phenotypes of several acallosal mutants appear similar, regardless of the presence or absence of hemisphere fusion (Stumpo et al., 1995; Brouns et al., 2000; Shen et al., 2002). Hemisphere fusion defects may result from failures in cell adhesion and/or migration. An early specification defect in the dorsal neural tube, which gives rise to the midline region where forebrain commissures form, may also manifest in later defects in commissure formation. Furthermore, because Mena and VASP are extensively expressed by the affected neurons as well as the midline glia, axonal pathway defects may result from the absence of Ena/VASP function in the neurons, glia, or both. Additional experiments are required to dissect the cellautonomous role of Ena/VASP proteins in callosal axon guidance.

In the visual system, high levels of Mena protein detected on retinal axons suggest that Mena may act cell autonomously in retinal axon guidance. In contrast to dorsal-forming forebrain commissures, optic chiasm defects are not associated with midline defects. Both slit and robo are expressed in the ventral diencephalon, anterior and posterior to where the chiasm forms (Erskine et al., 2000). However, Slit1/2 double mutants exhibit a phenotype that is very different from that observed in Mena mutants. In these embryos, axons form an anterior ectopic chiasm and make dorsoventral guidance errors but generally do not stray posteriorly (Plump et al., 2002). In zebrafish, robo2 is expressed in the retina, and the phenotype of the robo2 mutant astray is characterized by widespread retinal guidance errors (Fricke et al., 2001). Interestingly, however, the astray phenotype does not mirinsets, $600 \mu \mathrm{m}$.
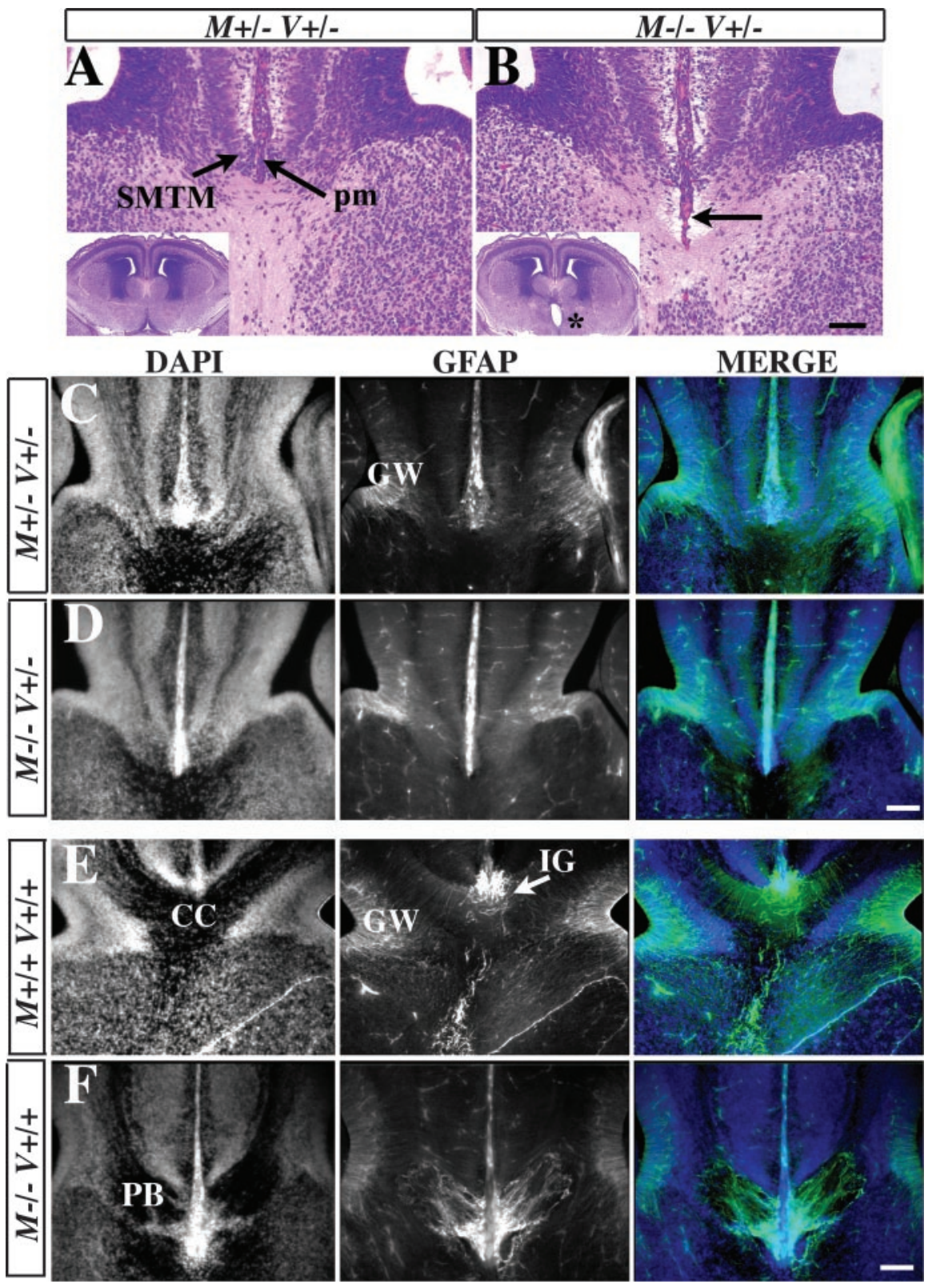

Figure 6. Midline development. $A, B, \mathrm{H} / \mathrm{E}$-stained coronal sections of $\mathrm{E} 16.5$ brains. Cerebral hemispheres are not fused properly in the mutant $M^{-/-} V^{+/-}$brain $(A)$ compared with the control brain $(B)$. The walls of the SMTM bend medially and fuse with the pial membrane (pm) in control brains. However, in mutant brains, the walls of the SMTM bend medially, but the hemispheres do not properly fuse because of the ventrally penetrating pial membrane $(B$, arrow). In the mutant diencephalon, a gap is present where normally the walls of the thalamus meet, forming the interthalamic adhesion ( $B$, asterisk). $C-F$, Midline glia are examined in control and mutant brains by anti-GFAP immunohistochemistry. C, D, At E16.5, GW development is similar in control $(C)$ and mutant $(D)$ brains. Glial processes of the GW extend from the lateral ventricles toward the midline. $E$, $F$, In the E17.5 control brains $(E)$, the GW and IG glia are well developed. The CC forms dorsal to the GW. In the E17.5 mutant brains $(F)$, the GW is less pronounced. Misrouted callosal axons form Probst bundles (PB) positioned ventral to the GW. Displaced IG glia, which are normally located at the midline where the hemispheres fused, appear to extend GFAP-positive processes into the PB. Scale bars: $100 \mu \mathrm{m}$;

ror the mouse Slit1/2 phenotype. Because both Robo1 and Robo2 are expressed in the mouse retina (Erskine et al., 2000; Niclou et al., 2000; Ringstedt et al., 2000; Fricke et al., 2001), analysis of Robo mutants may clarify whether Mena acts in this pathway.

\section{Redundant functions of Ena/VASP proteins}

Functional similarity between Ena/VASP proteins is demonstrated by the ability of any family member to rescue the random cell motility defects of cultured Ena/VASP-deficient fibroblasts 


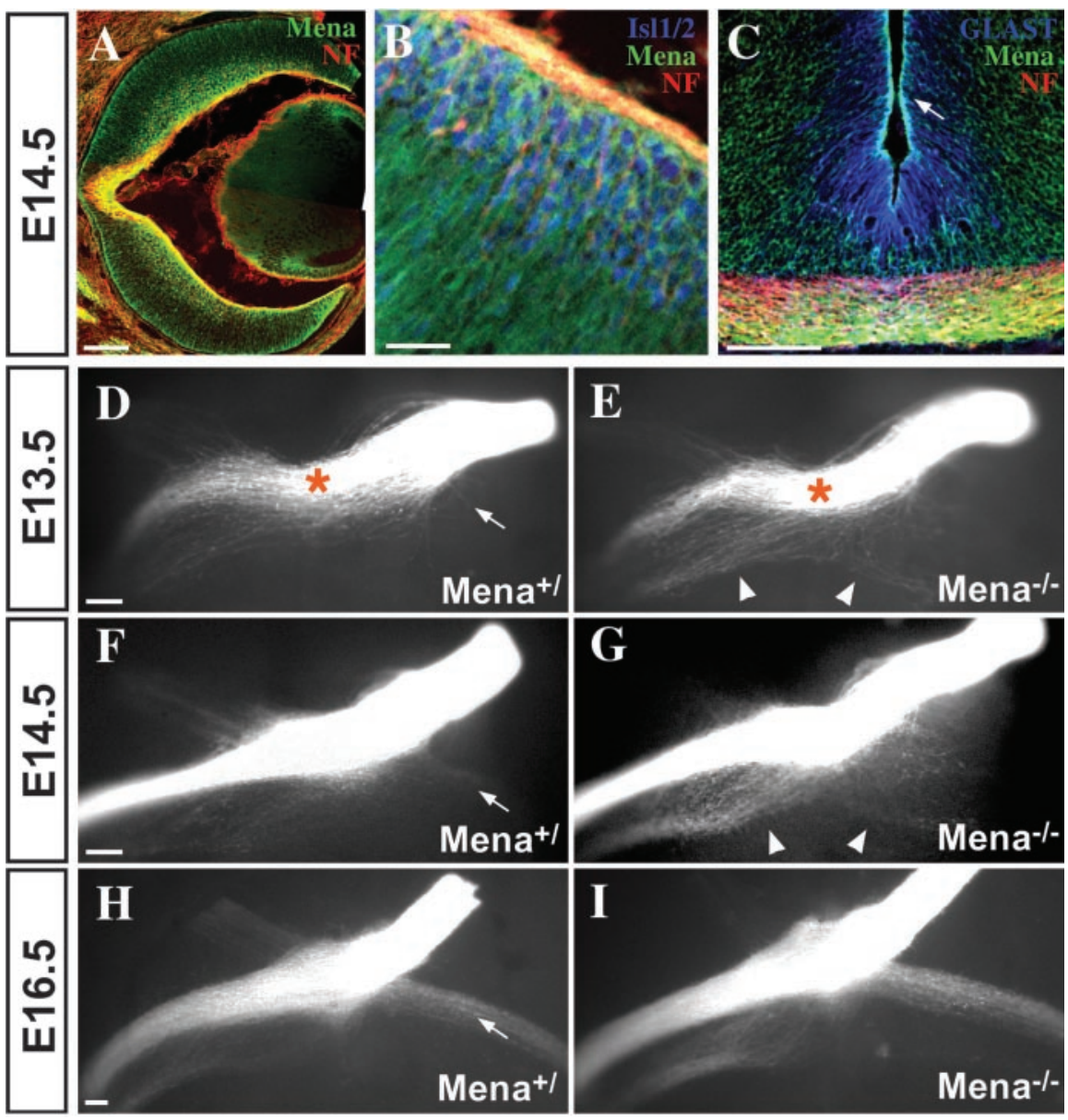

Figure 7. Role of Mena in optic chiasm development. $A-C$, Expression of Mena protein in the E14.5 mouse visual system. $A$, Mena protein is expressed throughout the developing retina but is most abundant in the RGC layer. The highest levels are found on RGC axons, which are positive for neurofilament (NF). B, High-magnification images of a coronal section of retina, demonstrating

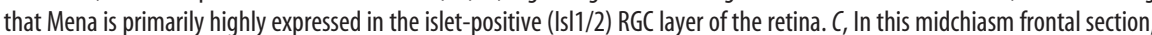
NF-positive RGC axons at the chiasm midline express Mena as well. Mena is also found at lower levels throughout the ventral diencephalon, in both the neurons and GLAST-positive midline glia (arrow) of the chiasm region. D-I, Whole-mount ventral views of the optic chiasm in control $(D, F, H)$ and Mena $^{-I}$ - littermates $(E, G, I)$ as revealed by unilateral anterograde labeling with Dil. In control embryos, the axons in the chiasm region are generally tightly fasciculated, particularly at older ages $(H)$. The majority of axons cross the midline $(D, E$, asterisks) to project to the contralateral side of the brain, although a minority project ipsilaterally $(D$, $F, H$, arrows). In Mena ${ }^{-1-}$ mutants, many axons become defasciculated at the midline and stray posteriorly ( $E, G$, arrowheads), giving the appearance of a double optic tract. This phenotype is fully penetrant, but exhibits variable expressivity and is generally most severe at younger ages $(E, G)$. Dorsal is at the top in $A-C$. Anterior is at the top in $D-I$. Scale bars: $A, C-I, 100 \mu \mathrm{m} ; B, 25 \mu \mathrm{m}$.

(Loureiro et al., 2002). Deletion of Mena and VASP reveals additional phenotypes not observed in either single knock-out animal. It is likely that in $M^{-/-} V^{-/-}$animals, expression of the third family member, EVL, masks the requirement for Ena/VASP function in other cell types. For example, expression of a construct that dominantly interferes with the function of all Ena/ VASP family members specifically in migrating neocortical neurons results in their misplacement within the neocortex (Goh et al., 2002). In a different mouse model, overexpression of a C-terminal fragment of VASP specifically in keratinocytes results in transgenic mice with skin defects (Vasioukhin et al., 2000). Cortical lamination and skin defects are not detected in the present study. This suggests that the continued expression of EVL alone is likely sufficient for proper development of many tissues in $M^{-1-} V^{-1-}$ animals. Transgenic strategies that inhibit the function of all Ena/VASP proteins in a temporal and cell typespecific manner will be critical to study the cell-autonomous function of Ena/VASP in a variety of cell types and processes.

\section{References}

Aszodi A, Pfeifer A, Ahmad M, Glauner M, Zhou XH, Ny L, Andersson KE, Kehrel B, Offermanns S, Fassler R (1999) The vasodilator-stimulated phosphoprotein (VASP) is involved in cGMPand CAMP-mediated inhibition of agonistinduced platelet aggregation, but is dispensable for smooth muscle function. EMBO J 18:37-48. Bagri A, Marin O, Plump AS, Mak J, Pleasure SJ Rubenstein JL, Tessier-Lavigne M (2002) Slit proteins prevent midline crossing and determine the dorsoventral position of major axonal pathways in the mammalian forebrain Neuron 33:233-248.

Bashaw GJ, Kidd T, Murray D, Pawson T, Goodman CS (2000) Repulsive axon guidance: Abelson and Enabled play opposing roles downstream of the roundabout receptor. Cell 101:703-715.

Bear JE, Svitkina TM, Krause M, Schafer DA Loureiro JJ, Strasser GA, Maly IV, Chaga OY, Cooper JA, Borisy GG, Gertler FB (2002) Antagonism between Ena/VASP proteins and actin filament capping regulates fibroblast motility. Cell 109:509-521.

Bentley D, Toroian-Raymond A (1986) Disoriented pathfinding by pioneer neurone growth cones deprived of filopodia by cytochalasin treatment. Nature 323:712-715.

Brouns MR, Matheson SF, Hu KQ, Delalle I, Caviness VS, Silver J, Bronson RT, Settleman J (2000) The adhesion signaling molecule p190 RhoGAP is required for morphogenetic processes in neural development. Development 127:4891-4903

Colavita A, Culotti JG (1998) Suppressors of ectopic UNC-5 growth cone steering identify eight genes involved in axon guidance in Caenorhabditis elegans. Dev Biol 194:72-85.

Colello RJ, Guillery RW (1990) The early development of retinal ganglion cells with uncrossed axons in the mouse: retinal position and axonal course. Development 108:515-523.

Cremer H, Lange R, Christoph A, Plomann M, Vopper G, Roes J, Brown R, Baldwin S, Kraemer P, Scheff S, Barthels D, Bajewsky K, Wille $\mathrm{W}$ (1994) Inactivation of the N-CAM gene in mice results in size reduction of the olfactory bulb and deficits in spatial learning. Nature 367:455-459.

Davidson LA, Keller RE (1999) Neural tube closure in Xenopus laevis involves medial migration, directed protrusive activity, cell intercalation and convergent extension. Development 126:4547-4556.

De Arcangelis A, Mark M, Kreidberg J, Sorokin L, Georges-Labouesse E (1999) Synergistic activities of alpha3 and alpha6 integrins are required during apical ectodermal ridge formation and organogenesis in the mouse. Development 126:3957-3968.

Dickson BJ (2002) Molecular mechanisms of axon guidance. Science 298 1959-1964.

Erskine L, Williams SE, Brose K, Kidd T, Rachel RA, Goodman CS, TessierLavigne M, Mason CA (2000) Retinal ganglion cell axon guidance in the mouse optic chiasm: expression and function of robos and slits. J Neurosci 20:4975-4982.

Fazeli A, Dickinson SL, Hermiston ML, Tighe RV, Steen RG, Small CG Stoeckli ET, Keino-Masu K, Masu M, Rayburn H, Simons J, Bronson RT, Gordon JI, Tessier-Lavigne M, Weinberg RA (1997) Phenotype of mice lacking functional Deleted in colorectal cancer (Dcc) gene. Nature 386:796-804

Fricke C, Lee JS, Geiger-Rudolph S, Bonhoeffer F, Chien CB (2001) astray, a zebrafish roundabout homolog required for retinal axon guidance. Science 292:507-510. 
Gambaryan S, Hauser W, Kobsar A, Glazova M, Walter U (2001) Distribution, cellular localization, and postnatal development of VASP and Mena expression in mouse tissues. Histochem Cell Biol 116:535-543.

Gertler FB, Doctor JS, Hoffmann FM (1990) Genetic suppression of mutations in the Drosophila abl proto-oncogene homolog. Science 248:857-860.

Gertler FB, Niebuhr K, Reinhard M, Wehland J, Soriano P (1996) Mena, a relative of VASP and Drosophila Enabled, is implicated in the control of microfilament dynamics. Cell 87:227-239.

Gitai Z, Yu TW, Lundquist EA, Tessier-Lavigne M, Bargmann CI (2003) The netrin receptor UNC-40/DCC stimulates axon attraction and outgrowth through enabled and, in parallel, Rac and UNC-115/AbLIM. Neuron 37:53-65.

Godement P, Salaun J, Mason CA (1990) Retinal axon pathfinding in the optic chiasm: divergence of crossed and uncrossed fibers. Neuron 5:173-186.

Godement P, Wang LC, Mason CA (1994) Retinal axon divergence in the optic chiasm: dynamics of growth cone behavior at the midline. J Neurosci 14:7024-7039.

Goh KL, Cai L, Cepko CL, Gertler FB (2002) Ena/VASP proteins regulate cortical neuronal positioning. Curr Biol 12:565-569.

Grevengoed EE, Loureiro JJ, Jesse TL, Peifer M (2001) Abelson kinase regulates epithelial morphogenesis in Drosophila. J Cell Biol 155:1185-1198.

Grevengoed EE, Fox DT, Gates J, Peifer M (2003) Balancing different types of actin polymerization at distinct sites: roles for Abelson kinase and Enabled. J Cell Biol 163:1267-1279.

Han YH, Chung CY, Wessels D, Stephens S, Titus MA, Soll DR, Firtel RA (2002) Requirement of a vasodilator-stimulated phosphoprotein family member for cell adhesion, the formation of filopodia, and chemotaxis in dictyostelium. J Biol Chem 277:49877-49887.

Hauser W, Knobeloch KP, Eigenthaler M, Gambaryan S, Krenn V, Geiger J, Glazova M, Rohde E, Horak I, Walter U, Zimmer M (1999) Megakaryocyte hyperplasia and enhanced agonist-induced platelet activation in vasodilator-stimulated phosphoprotein knockout mice. Proc Natl Acad Sci USA 96:8120-8125.

Hogan B, Beddington R, Constantini F, Lacy E (1994) Immunocytochemistry of whole mount embryos. In: Manipulation of the mouse embryo (Hogan B, Beddington R, Constantini F, Lacy E, eds), pp 340-367. Plainview, NY: Cold Spring Harbor Laboratory.

Holmberg J, Clarke DL, Frisen J (2000) Regulation of repulsion versus adhesion by different splice forms of an Eph receptor. Nature 408:203-206.

Howe AK, Hogan BP, Juliano RL (2002) Regulation of vasodilatorstimulated phosphoprotein phosphorylation and interaction with Abl by protein kinase A and cell adhesion. J Biol Chem 277:38121-38126.

Juriloff DM, Harris MJ (2000) Mouse models for neural tube closure defects. Hum Mol Genet 9:993-1000.

Koleske AJ, Gifford AM, Scott ML, Nee M, Bronson RT, Miczek KA, Baltimore D (1998) Essential roles for the Abl and Arg tyrosine kinases in neurulation. Neuron 21:1259-1272.

Krause M, Dent EW, Bear JE, Loureiro JJ, Gertler FB (2003) ENA/VASP PROTEINS: regulators of the actin cytoskeleton and cell migration. Annu Rev Cell Dev Biol 19:541-564.

Lanier LM, Gates MA, Witke W, Menzies AS, Wehman AM, Macklis JD, Kwiatkowski D, Soriano P, Gertler FB (1999) Mena is required for neurulation and commissure formation. Neuron 22:313-325.

Lebrand C, Dent EW, Strasser GA, Lanier LM, Krause M, Svitkina TM, Borisy GG, Gertler FB (2004) Critical role of Ena/VASP proteins for filopodia formation in neurons and in function downstream of netrin-1. Neuron 42:37-49.

Livy DJ, Wahlsten D (1997) Retarded formation of the hippocampal commissure in embryos from mouse strains lacking a corpus callosum. Hippocampus 7:2-14.

Loureiro JJ, Rubinson DA, Bear JE, Baltus GA, Kwiatkowski AV, Gertler FB
(2002) Critical roles of phosphorylation and actin binding motifs, but not the central proline-rich region, for Ena/vasodilator-stimulated phosphoprotein (VASP) function during cell migration. Mol Biol Cell 13:2533-2546.

Meyer G, Feldman EL (2002) Signaling mechanisms that regulate actinbased motility processes in the nervous system. J Neurochem 83:490-503.

Morriss-Kay G, Tuckett F (1985) The role of microfilaments in cranial neurulation in rat embryos: effects of short-term exposure to cytochalasin D. J Embryol Exp Morphol 88:333-348.

Niclou SP, Jia L, Raper JA (2000) Slit2 is a repellent for retinal ganglion cell axons. J Neurosci 20:4962-4974.

Ozaki HS, Wahlsten D (1993) Cortical axon trajectories and growth cone morphologies in fetuses of acallosal mouse strains. J Comp Neurol 336:595-604.

Plump AS, Erskine L, Sabatier C, Brose K, Epstein CJ, Goodman CS, Mason CA, Tessier-Lavigne M (2002) Slit1 and Slit2 cooperate to prevent premature midline crossing of retinal axons in the mouse visual system. Neuron 33:219-232.

Probst M (1901) Uber den Bau des balkenlosen Grobhirns, sowie uber Mikrogyrie und Heterotypie der grauen. Substanz Arch Psychiatr 709-786.

Radice GL, Rayburn H, Matsunami H, Knudsen KA, Takeichi M, Hynes RO (1997) Developmental defects in mouse embryos lacking N-cadherin. Dev Biol 181:64-78.

Ringstedt T, Braisted JE, Brose K, Kidd T, Goodman C, Tessier-Lavigne M, O'Leary DD (2000) Slit inhibition of retinal axon growth and its role in retinal axon pathfinding and innervation patterns in the diencephalon. J Neurosci 20:4983-4991.

Serafini T, Colamarino SA, Leonardo ED, Wang H, Beddington R, Skarnes WC, Tessier-Lavigne M (1996) Netrin-1 is required for commissural axon guidance in the developing vertebrate nervous system. Cell 87:1001-1014.

Shen Y, Mani S, Donovan SL, Schwob JE, Meiri KF (2002) Growthassociated protein-43 is required for commissural axon guidance in the developing vertebrate nervous system. J Neurosci 22:239-247.

Shu T, Richards LJ (2001) Cortical axon guidance by the glial wedge during the development of the corpus callosum. J Neurosci 21:2749-2758.

Shu T, Sundaresan V, McCarthy MM, Richards LJ (2003) Slit2 guides both precrossing and postcrossing callosal axons at the midline in vivo. J Neurosci 23:8176-8184.

Smith JL, Schoenwolf GC (1997) Neurulation: coming to closure. Trends Neurosci 20:510-517.

Song HJ, Poo MM (1999) Signal transduction underlying growth cone guidance by diffusible factors. Curr Opin Neurobiol 9:355-363.

Sretavan DW (1990) Specific routing of retinal ganglion cell axons at the mammalian optic chiasm during embryonic development. J Neurosci 10:1995-2007.

Stumpo DJ, Bock CB, Tuttle JS, Blackshear PJ (1995) MARCKS deficiency in mice leads to abnormal brain development and perinatal death. Proc Natl Acad Sci USA 92:944-948.

Tani K, Sato S, Sukezane T, Kojima H, Hirose H, Hanafusa H, Shishido T (2003) Abl interactor 1 promotes tyrosine 296 phosphorylation of mammalian enabled (Mena) by c-Abl kinase. J Biol Chem 278:21685-21692.

Vasioukhin V, Bauer C, Yin M, Fuchs E (2000) Directed actin polymerization is the driving force for epithelial cell-cell adhesion. Cell 100:209-219.

Wahlsten D (1981) Prenatal schedule of appearance of mouse brain commissures. Brain Res 227:461-473.

Wills Z, Bateman J, Korey CA, Comer A, Van Vactor D (1999) The tyrosine kinase $\mathrm{Abl}$ and its substrate enabled collaborate with the receptor phosphatase Dlar to control motor axon guidance. Neuron 22:301-312.

Ybot-Gonzalez P, Copp AJ (1999) Bending of the neural plate during mouse spinal neurulation is independent of actin microfilaments. Dev Dyn 215: 273-283. 